\title{
ESTIMATIONS OF CARBON FOOTPRINT FROM ELECTRICITY CONSUMPTION DURING COVID-19 LOCKDOWN AND PRE-LOCKDOWN IN BUTUAN CITY
}

\author{
LC. S. Asube ${ }^{1,2}$, R. L. Sinadjan ${ }^{2}$
}

\begin{abstract}
${ }^{1}$ Caraga Center for Geo-Informatics, Caraga State University, Ampayon, Butuan City, 8600, Philippines, - lsasube@ carsu.edu.ph
${ }^{2}$ Department of Geodetic Engineering, College of Engineering and Geosciences, Caraga State University, Ampayon, Butuan City, 8600, Philippines - roland.seenzone123@gmail.com
\end{abstract}

KEY WORDS: Carbon Footprint, Carbon dioxide emission, electricity consumption, COVID-19 lockdown \& pre-lockdown period, Geographic Information System (GIS), spatial distribution

\begin{abstract}
:
The electricity consumption for commercial, residential, and industrial sectors is considered the primary cause of increasing carbon dioxide emissions. To calculate the carbon footprint, the researcher used Carbon Footprint Ltd. This study aims to quantify the carbon footprint associated with the consumption of electricity by sectors (residential, commercial, industrial, public buildings, and streetlights) in Butuan City during the pre-lockdown period (January and February), and then compare these with the carbon footprint calculated during the lockdown period (March and April 2020). A GIS-based approach was applied to generate the spatial distribution across the 86 barangays of Butuan City. The study findings that the carbon footprint in the lockdown period is $\sim-17 \%$ lower than the mean carbon footprint calculated for the pre-lockdown period. In absolute values, the total estimated carbon footprint during the prelockdown and lockdown period was $\sim 10,947 \mathrm{mtCo} 2 \mathrm{e}$ and $\sim 9,138 \mathrm{mtCo} 2 \mathrm{e}$, respectively. Furthermore, the findings imply that the central and northern areas have the highest impact of savings on average $\sim 130 \mathrm{mtCo} 2 \mathrm{e}$ of greenhouse gas avoided by barangays. This research provides quantitative insight to understand the measured generated in lockdown and pre-lockdown periods.
\end{abstract}

\section{INTRODUCTION}

Coronavirus disease 2019 (COVID-19) is a coronavirus-related viral disease that produces severe acute respiratory syndrome (Zhu et al., 2019). Much recent research has investigated the consequences of company collapse during the COVID-19 pandemic. Micro, small, and medium enterprise outbreaks, showing a significant drop in carbon dioxide emissions connected with fewer anthropogenic activities (Carugno et al., 2020) and (Contini and Costable, 2020). ArcGIS is an integrated collection of GIS software products that provides a standardsbased platform for spatial analysis, data management, and mapping (ESR Institution, 2009). GIS is a geographic information system that captures, stores, manipulates, analyzes, manages, and displays spatial or geographic data (Biradar, 2005). The coronavirus effect had a significant negative impact on the overall carbon footprint in terms of electricity consumption. The amount of carbon emission has decreased significantly (Mylenka, 2020).

COVID-19 lockdown in Butuan City recorded on March 11, 2020. There was a sudden decrease in electricity use in businesses since workplaces and manufacturing factories completely stopped production or made partial work and production. The coronavirus effect has a significant negative impact on overall electricity consumption demand, and the amount consumed has decreased significantly (T. Mylenka, 2020). Lockdown in Butuan City commercial, industrial, and residential activities strictly connected with the consumption of electricity and their greenhouse gas emission potentially has enormous effects on the associated carbon footprint.

This study aims to estimate the carbon footprint from electricity consumption during the COVID-19 lockdown (March 2020 and April 2020) and pre-lockdown (January 2020 and February 2020) in Butuan City. It also aims to generate a map on the spatial distribution of carbon footprint in Butuan City and correlate the results during the lockdown and pre-lockdown period. The study was limited only to estimating carbon emission from electricity consumption during COVID-19 pre-lockdown period (January \& February 2020) and lockdown period (March and April 2020).

The study was useful to the government research and development programs in the city to determine how carbon emission of electricity consumption during the COVID-19 starts in Butuan City. It is also utilized to assess the impact of global warming on environmental sustainability. This study was also beneficial to the community by raising their environmental awareness in reducing the impact of global warming and the attitude towards proper and responsible energy consumers.

\section{METHODS}

The study's methodology consists of five major activities: data acquisition, calculation of carbon footprint using Carbon Footprint Ltd, GIS processing, spatial distribution map of carbon footprint during pre-lockdown and lockdown period, and statistical map of carbon footprint across carbon footprint 86 barangays in Butuan City. The statistical map was produced to estimate the carbon footprint of Butuan City during the COVID19 pandemic.

\subsection{Data Acquisition}

Electricity consumption data, population density, and geographical information of Butuan City are the main three categories of data used in this study. Electricity consumption data such as during the COVID-19 pre-lockdown and lockdown period, a monthly consumption between January and April 2020, were collected from Agusan del Norte Electric Cooperative (ANECO). The Population Density of Butuan in every barangay 
is also collected in the Philippine Statistic Authority (PSA). The geographical data of Butuan City region boundary and barangay attributes were downloaded from the internet.

\subsection{Calculation of Carbon Footprint}

To characterize and map the carbon footprint of electricity consumption during the COVID-19 pre-lockdown period and lockdown period in Butuan City, Co2 equivalents data were used. There are many online carbon footprint calculators to calculate the carbon footprint in terms of carbon dioxide emission from electricity consumption. This study focuses only on one online carbon footprint calculator for the consistency of the accuracy of the results, and this tool is up to date compared to other carbon footprint calculators. It is considered that some of the carbon footprint calculators were limited in terms of the country's availability. The more accurate carbon footprint calculation from electric consumption, as the electricity (kWh) factor, depends on how electricity is generated in the specific country or region.

The manual calculation to have the carbon footprint from electricity consumption using Equation 1 and carbon footprint per capita during the lockdown and pre-lockdown period using Equation 2 of the total carbon footprint over the total population (R. Marc, 2015)

$$
m t C o 2 e=k W h \times 998.4 \frac{l b s}{M W h} \times\left(\frac{1 M W h}{(1-0.069 M W h)}\right) \times
$$$$
\left(\frac{1 M W h}{1,000 k W h}\right) \times\left(\frac{1 m t}{2,204.6 l b}\right)
$$

$$
\text { co2e per capita }=\frac{\text { Total carbon footprint }}{\text { Total Population }}
$$

In this study, the researcher used $0.579 \mathrm{kgCo} 2 / \mathrm{kWh}$ electricity factor since it is the electricity factor of the Philippines. Carbon Footprint Ltd has credibility as a tool for the estimation of a carbon footprint. Some studies' findings were used in the recent study (Viachaslau Filimonau et al., 2020). "The Carbon Footprint of UK University during COVID-19 lockdown" (V. Richard et al, 2020). The study entitled "An evaluation of online carbon footprint calculator", analyzed and compare 31 online carbon footprint calculators to identify the most essential inputs and user's engagement features, through the findings and develop the best example of carbon footprint calculator is Carbon Footprint Ltd (John Mulrow et al., 2017). Carbon Footprint Ltd was also certified by the ISO 14001:2015 (Cert No. 538803), which specifies the requirements for an environmental management system that an organization can use to enhance its environmental performance. ISO 9001:2015 (Cert No. 577702) strives to promote customer contentment through practical system application, including system improvement procedures and verification of system adherence to customer and applicable legislative and regulatory requirements.

\subsection{Geographic Information System (GIS) Processing}

The Geographic Information System (GIS) is the main source for processing the spatial distribution of carbon footprint to characterize and map the carbon footprint from electricity consumption. The researcher used ArcGIS software and Butuan City shapefile data to validate the location of each barangay of Butuan City.
A Geographic Information System (GIS) is a computer system for capturing, storing, checking, and displaying data related to positions on Earth's surface. GIS can use any information that includes location, especially in the activity sites in Butuan City. Using the layer symbology features in this process, the researcher was classified the different carbon footprints of each barangay. The GIS technique used in this activity serves as a valuable decision support tool for identifying the carbon footprint of vulnerable areas to rising carbon dioxide emissions. The map generation that estimates the carbon footprint during the COVID19 lockdown and pre-lockdown visualizes Butuan City's barangay.

2.3.1 Importing Data. This process is applied to extract or record the computed carbon emission equivalent data from Microsoft excel. In this study, this process is essential since the data was inputted manually from Microsoft excel to avoid error, double counting of carbon dioxide emission equivalents. Less time-consuming, importing data to attribute tables from Microsoft excel is significant. It is highly required before any further manipulation and analysis of the image data to extract specific information.

2.3.2 Symbology features properties. The fundamental process of this activity is the editing of symbology features of an image to display data more effectively for subsequent visual interpretation. Transforming raw data to usable information and representing geographic features on a map can vary symbology according to values in the layer's attribute table. In these activity quantities, gradual colors symbolize the carbon footprint show quantitative differences in feature values with a range of colors, and charts for comparing the carbon footprint of COVID-19 lockdown and pre-lockdown period. The researcher used the graduated color scheme to show the geographic spread of the same phenomenon during the COVID-19 lockdown and prelockdown. A geometric interval classification scheme was used in this study to ensure that each class range has about the same number of values and that the change between intervals is relatively consistent. It is possible to see the difference between the pre-lockdown to lockdown period and equal distribution in the study area.

\subsection{Spatial Distribution of Co2-equivalents}

The spatial distribution of carbon dioxide equivalents from electric consumption flows was collected, calculated, elaborated, and presented a map at the scale of each barangay of Butuan City. This type of geographical resolution was available only for electricity consumption, a monthly series consumption between January and April 2020. The disaggregate of the carbon footprint from January to April, a basic allocation assumption performed concerning the Co2-equivalents categories. The estimated carbon footprint distribution during COVID-19 lockdown and prelockdown using ArcGIS software. 86 barangays of Butuan City were used to allocate the carbon footprint over January to April.

\subsection{Spatial Distribution of Carbon Footprint (CF)}

The first phase is to import all sources into the GIS software of which ArcGIS is predominant. After inputting the sources into the software, the emission period should be identified. The GIS database contains information on the carbon dioxide equivalents during the COVID-19 lockdown and pre-lockdown. Using ArcGIS software, carbon footprint mapping was done, and the carbon dioxide equivalents were calculated from electricity use. Using the data carbon dioxide equivalents imported from excel, the spatial distribution of carbon footprint was determined. 


\section{RESULTS AND DISCUSSION}

\subsection{Carbon Footprint in the lockdown and pre-lockdown period}

The main findings of this study are that the carbon footprint $(\mathrm{CF})$ due to the electricity consumption occurring in Butuan City during the COVID-19 lockdown is diverse from the prelockdown period. The lockdown period from March to April 2020 is significantly lower than the carbon footprint calculated for pre-lockdown periods in the recent two months of January and February 2020. Compared to the total carbon footprint during the COVID-19 pre-lockdown to lockdown period, as shown in Figure 1, the overall reduction is approximately $-17 \%$. In absolute values, the total calculated carbon footprint during the pre-lockdown and lockdown period was $\sim 10,947$ and $\sim 9,138$, respectively.

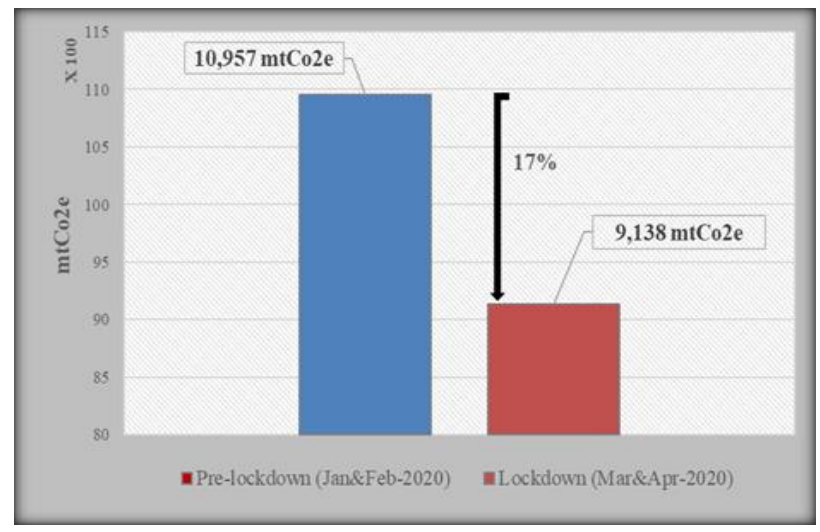

Figure 1. Comparison of the carbon footprint associated with electricity consumptions in pre-lockdown and lockdown period.

Figure 2 compares every sector's carbon dioxide emission in Butuan City during the COVID-19 pre-lockdown vs. lockdown period. In lockdown period residential increase of 5\% of carbon emission from the total carbon footprint, industrial decreased $14 \%$, commercial decreased of $-22 \%$, public buildings decreased $-10 \%$, and streetlights decreased by $-7 \%$. Almost all sectors reduced the carbon emission during the lockdown period.

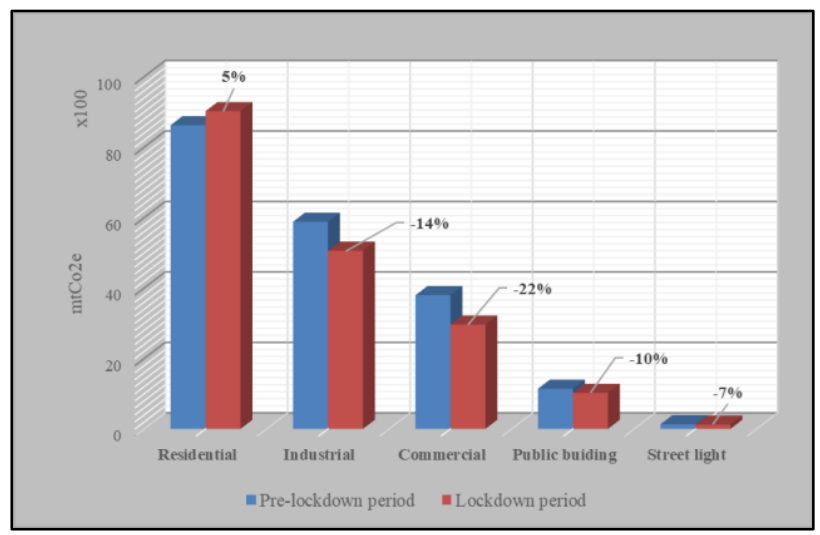

Figure 2. Comparison between the Butuan City carbon footprint trends associated in every sector of electricity consumption in pre-lockdown vs. lockdown periods.

In terms of the rate of reduction of carbon emissions associated with electricity consumption, Figure 3 shows the estimated total carbon footprint progress in 2020. They considered the trend in the pre-lockdown and lockdown phases and projected the carbon footprint over the lockdown period. It was highlighted that March and April 2020 are associated with the COVID-19 lockdown period. The difference between January to December 2020 (monthly consumption) was even lower in the lockdown period associated with March and April 2020 than in January and February 2020 (pre-lockdown period).

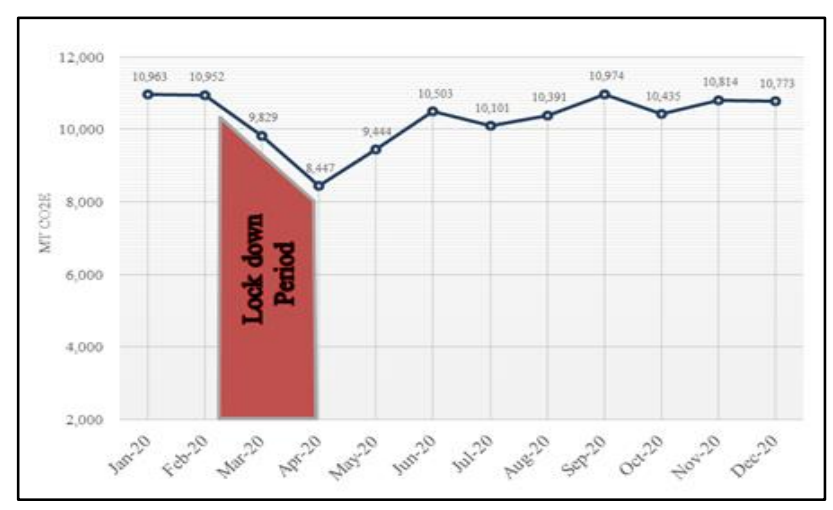

Figure 3. Monthly trend of the carbon footprint associated with electricity consumption from January to December 2020.

Figure 4 shows the projected total share of carbon footprint in every sector during the lockdown period. In the different sectors, residential had the highest total share of all sectors with 50 percent share from the total carbon footprint during the lockdown period. It was followed by the industrial sector with 28 percent, commercial with 16 percent, public buildings with 5 percent, and streetlights with 1 percent.

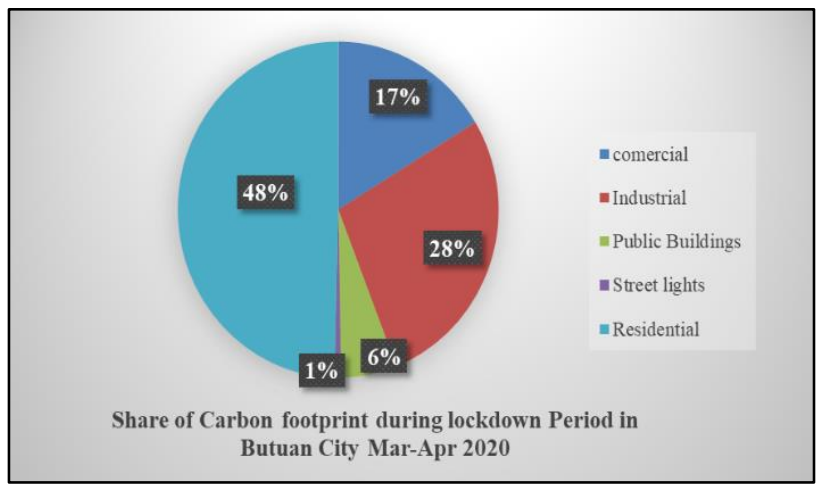

Figure 4. Disaggregation of the total carbon footprint by every sector relative to the lockdown period.

\subsection{Spatial Distribution of Carbon Footprint (CF)}

3.2.1 Pre-lockdown Period. The spatial distribution of carbon footprint during COVID-19 pre-lockdown across Butuan's 86 barangays shows an uneven spatial distribution of carbon footprint, as shown in Figure 5. It includes a tendency towards higher impact in the central \& northern areas and few exceptions in the southern, western and eastern areas. The highest carbon footprints are mainly concentrated in the areas which indicate the dark red color. 
Precisely, Barangay Libertad, Bayanihan, Villa Kananga, Imadejas, and Baan Km3, followed by Barangay San Vicente, Doongan, Ambago, Tandang sora, Urduja, Mahogany, Banza, Ampayon and Taguibo, and the lowest carbon footprint indicate the light red color including Barangay MJ Santos, Baobaoan, Bitanagan, Bugsukan, Camahayan, Dankias, Don Francisco, Maibo, Mandamo, Nongnong, Salvacion, and Barangay Sumile before COVID -19 lockdown period a month of January and February 2020.

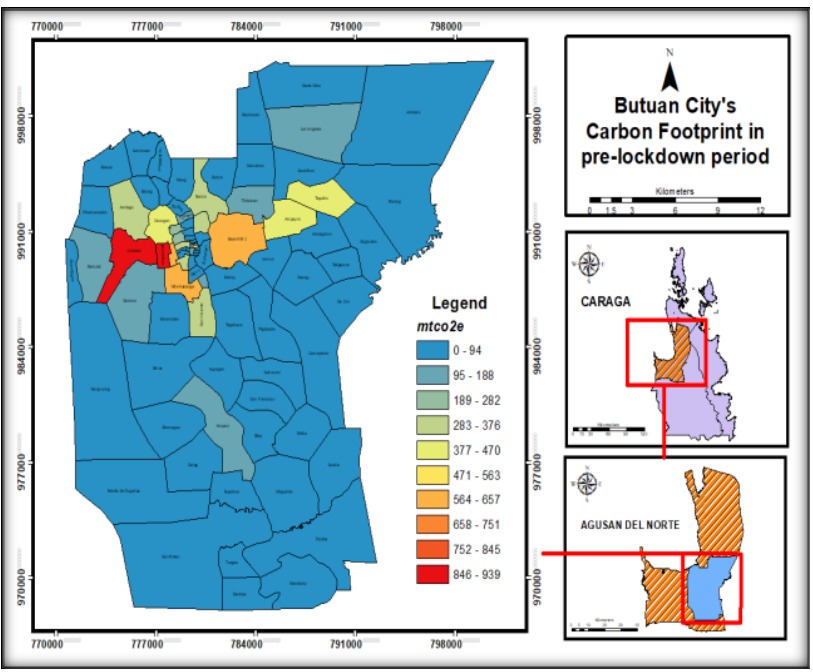

Figure 5. Spatial distribution of carbon footprint before COVID-19 lockdown (a month of January \& February2020) in Butuan City.

Barangay Bayanihan was the highest carbon footprint with 939 mtco2e from the total carbon footprint before the lockdown between January and February 2020. Barangay Libertad with the size of 852 mtco2e, Baan Km3 with 644 mtco2e, Villa Kananga with 592 mtco2e, Imadejas with 576 mtco2e, Urduja with 507 mtco2e, Doongan with 442 mtco2e, Taguibo with 440 mtco2e, Ampayon with 425 mtco2e, and Barangay Ambago with 374 mtco2e from the total carbon footprint before lockdown period. Barangay Mandamo had the lowest carbon footprint of $3 \mathrm{mtco} 2 \mathrm{e}$, Barangay Nongnong, then Maibu and Don Francisco with 4 mtco2e. Bitan-agan, Bugsukan, Mj Santos, and Sumile with 5 mtco2e, Camahayan and Dankias with 6 mtco2e, Baobaoan and Salvacion with 7 mtco2e, Bilay, Florida and San Mateo with 9 mtco2e, Aupagan and Bobon with 10 mtco2e, St Nino with 10, De-Oro, Maguinda, Manila de Bugabus and Pianing with 13 mtco2e, and Barangay Dulag with the size of $14 \mathrm{mtco} 2 \mathrm{e}$, from the total carbon footprint before lockdown period.

The most contributor to GHG emissions is barangay Bayanihan with a size making up 8.60 percent share of the total carbon footprint before the lockdown period in January and February 2020, as shown in Figure 6. Libertad came in second in terms of contributing the carbon footprint, with a 7.80 percent share. It was followed by Baan km.3 with 5.90 percent, Villa Kananga with 5.40 percent, Imadejas with 5.30 percent, Urduja with 4.60 percent, Doongan with 4.00 percent, Taguibo with 4.00 percent, Ampayon with 3.90 percent, and Ambago with 3.40 percent from the total carbon footprint. The remaining barangays each contributed less than $3.0 \%$.

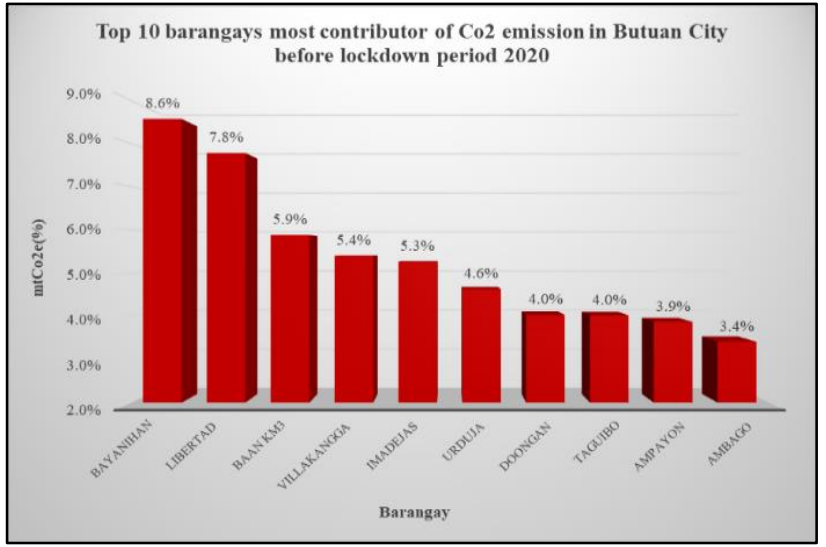

Figure 6. Top 10 most contributor of Carbon dioxide emission in Butuan City during COVID-19 Prelockdown Period.

3.2.2 Lockdown Period. The spatial distribution of carbon footprint during the COVID-19 lockdown period a month of March and April 2020 was shown in Figure 7. The highest carbon footprint was Barangay Libertad, Bayanihan, Baan Km3, and Villa Kananga. It was followed by Barangay Ambago, Doongan, Imadejas, Jose Rizal, San Vicente, Urduja, Banza, Mahogany, Ampayon, and Taguibo. These areas were located in the central and northern regions of Butuan City. The lowest carbon footprint was located in the southern, western, and eastern areas, Barangay Bogsokan, Baobaon, Camahayan, Don Francisco, Maibu, Sumile, Mandamo, Dankias, Bugabus, Bitan-agan, Nongnong, and MJ santos.

Barangay Libertad was the highest carbon footprint with 809 mtco2e, from the total carbon footprint before the lockdown period in January and February 2020. Barangay Bayanihan with 548 mtco2e, Baan Km3 with 547 mtco2e, Villa Kananga with 497 mtco2e, Imadejas with 397 mtco2e, Doongan with 376 mtco2e mtco2e, San Vicente with 376 mtco2e, Urduja with 370 mtco2e, Taguibo with 362, and Barangay Ampayon with 356 mtco2e, from the total carbon footprint before lockdown period. Barangay Mandamo and Don Francisco was the lowest carbon footprint with the size of $3 \mathrm{mtco} 2 \mathrm{e}$. This was followed by Barangay Sumile, Nongnong, and Maibu with 4 mtco2e, MJ santos, Dankias, Camahayan, Bugsukan, and Bitan-agan with 5 mtco2e from the total carbon footprint before the lockdown period.

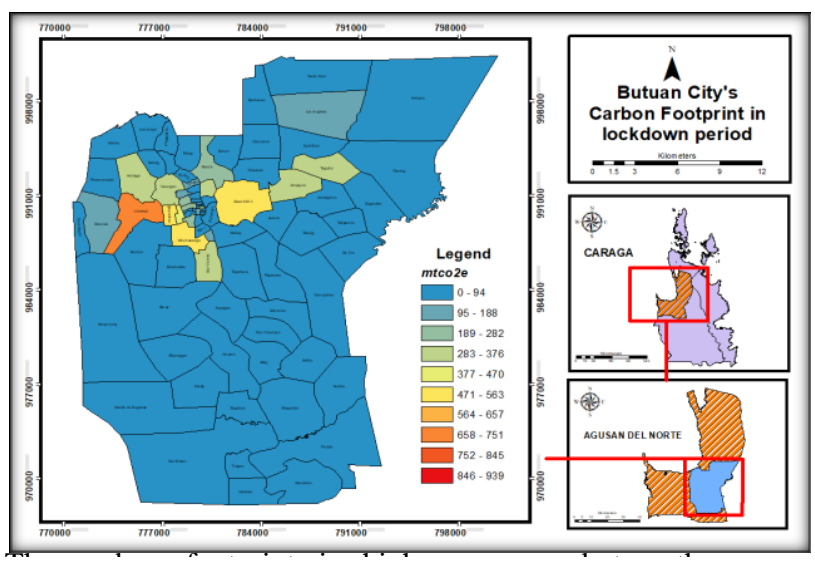

Figure 7. Spatial distribution of carbon footprint during COVID-19 lockdown (a month of April \& May-2020) in Butuan City. 
size making up 8.85 percent share of the total carbon footprint before the lockdown period a month of January and February 2020 (Figure 8).

Barangay Bayanihan was the second in terms of contribution of carbon footprint, with a 6 percent share. It was followed by Baan km.3 with 5.99 percent, Villa Kananga with 5.44 percent, Imadejas with 4.34 percent, Doongan with 4.11 percent, Urduja with 4.05 percent, San Vicente with 4.02 percent, Taguibo with 3.96 percent, and Ampayon with 3.93 percent from the total carbon footprint. The remaining barangays each contributed less than $3.0 \%$.

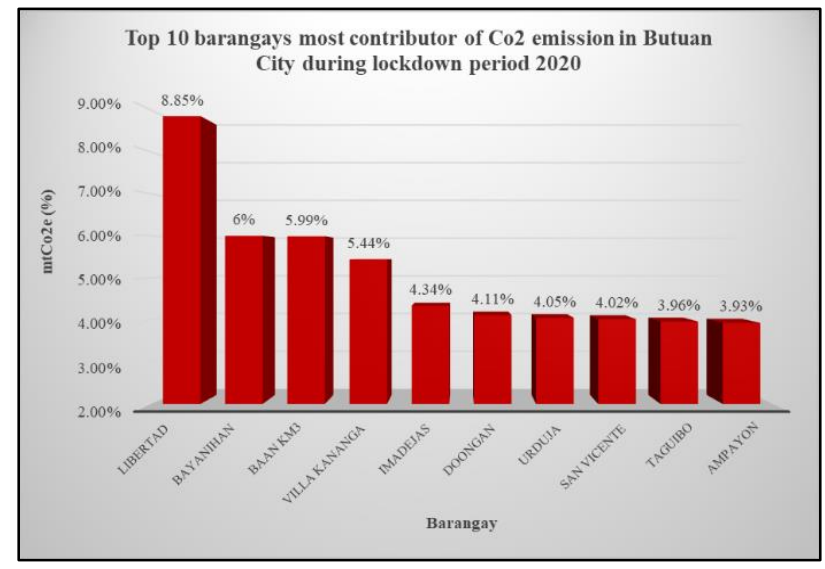

Figure 8. Top 10 most contributor of Carbon dioxide emission in Butuan City during COVID -19 Lockdown Period.

\subsection{Spatial Distribution of Carbon Footprint in every sector}

3.3.1 Residential Electricity Consumption. Figure 9 shows the spatial distribution of carbon footprint in residential electricity usage throughout the lockdown period throughout 86 . barangays in Butuan City.

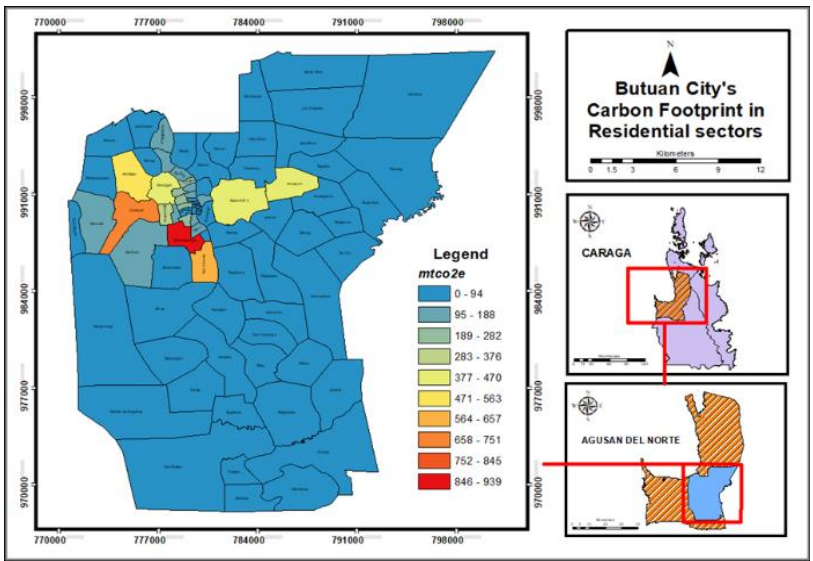

Figure 9. Spatial distribution of carbon footprint from residential electricity consumption during COVID-19 lockdown (a month of April \& May-2020) in Butuan City.

The spatial distribution of carbon footprint shows that the center area of Butuan City has the highest impact of carbon emission in the lockdown period. The barangay indicates the dark blue color represents the highest carbon footprint, especially in Villa Kananga which has 988 mtco2e from the total carbon footprint in the residential sector. It was followed by Barangay Libertad with 659 mtco2e, Ambago has 553 mtco2e, Baan km3 has 460 mtco2e, and Doongan has 455 mtco2e.

3.3.2 Industrial Electricity Consumption. Figure 10 shows the spatial distribution of carbon footprint from industrial electricity use in Butuan City's 86 barangays during the lockdown period. The figure shows a shift for a higher carbon footprint in the northern and western regions. Barangay Bayanihan, Taguibo, Baan $\mathrm{km} 3$ has the highest carbon footprint in the industrial sector, Bayanihan has $765 \mathrm{mtco} 2 \mathrm{e}$, Taguibo has $631 \mathrm{mtco} 2 \mathrm{e}$, and Baan km3 528 mtco2e.

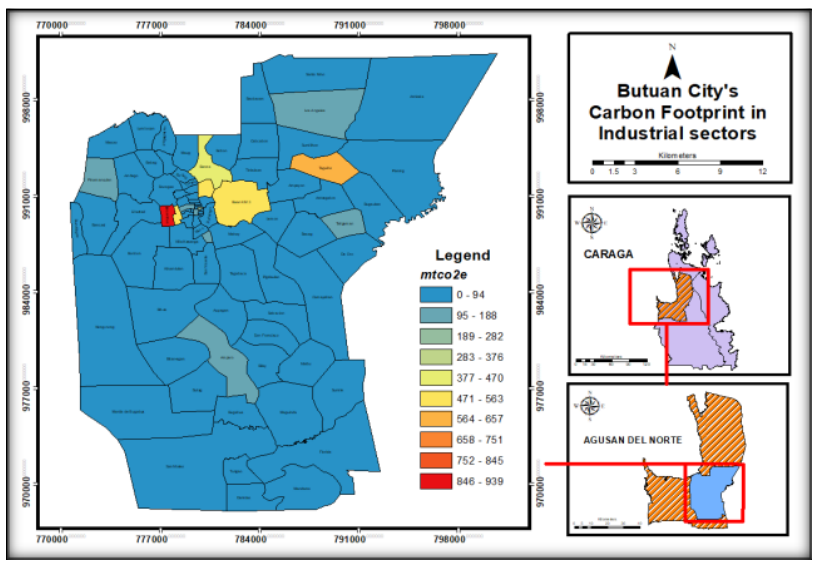

Figure 10. Spatial distribution of carbon footprint from Industrial electricity consumption during COVID-19 lockdown (a month of April \& May-2020) in Butuan City.

3.3.3 Commercial Electricity Consumption. Figure 11 shows the spatial distribution of carbon footprint from commercial electricity consumption during the lockdown period across 86 barangays' of Butuan City. The figure indicates that the dark blue color represents the highest carbon footprint. The light color indicates the lowest carbon footprint. Barangay Urduja, Libertad, and Bayanihan have the highest carbon footprint, 413 mtco2e, 295 mtco2e, and 291 myco2e.

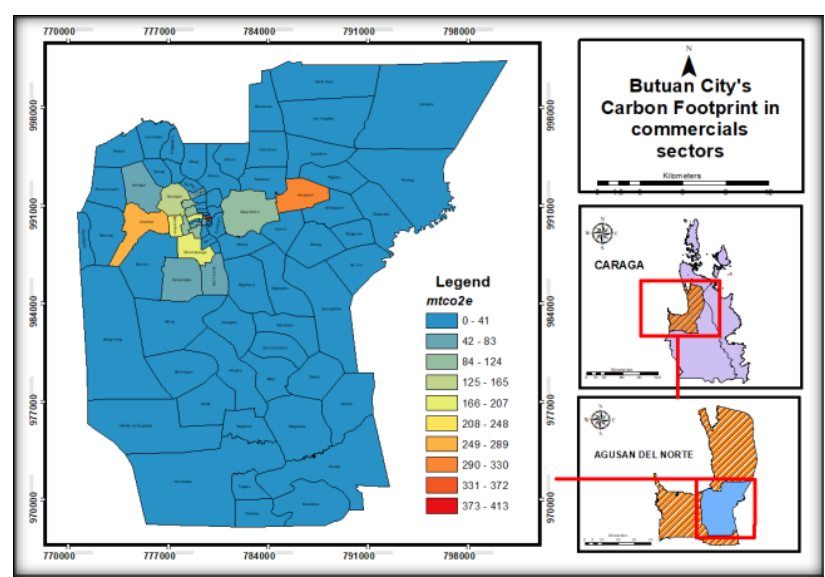

Figure 11. Spatial distribution of carbon footprint from commercial electricity consumption during COVID-19 lockdown (a month of April \& May-2020) in Butuan City. 
3.3.4 Public Building Electricity Consumption. Figure 12 shows the spatial distribution of carbon footprint from public building electricity consumption during the lockdown period across 86 barangays' of Butuan City. The figure shows that the higher carbon footprint indicates the dark blue color. The highest carbon footprint was Barangay Ampayon, Doongan, and Libertad, with 176 mtco2e, 47mtco2e, and 139 mtco2e, respectively.

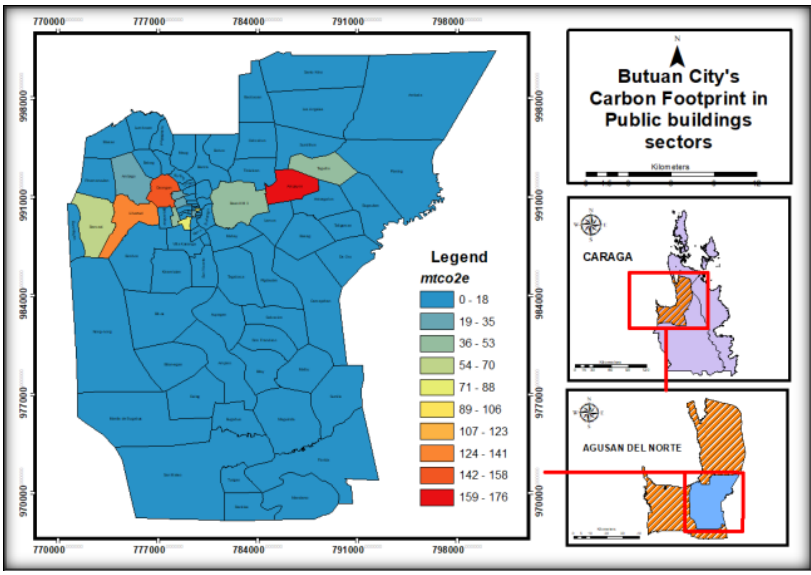

Figure 12. Spatial distribution of carbon footprint from public building electricity consumption during COVID-19 lockdown (a month of April \& May-2020) in Butuan City.

3.3.5 Streetlights Electricity Consumption. Figure 13 shows the spatial distribution of carbon footprint from streetlights' electricity consumption during the lockdown period across 86 barangays' of Butuan City. The figure shows that the highest carbon footprint in streetlights electricity consumption was Barangay Libertad, with four mtco2e from the total carbon footprint.

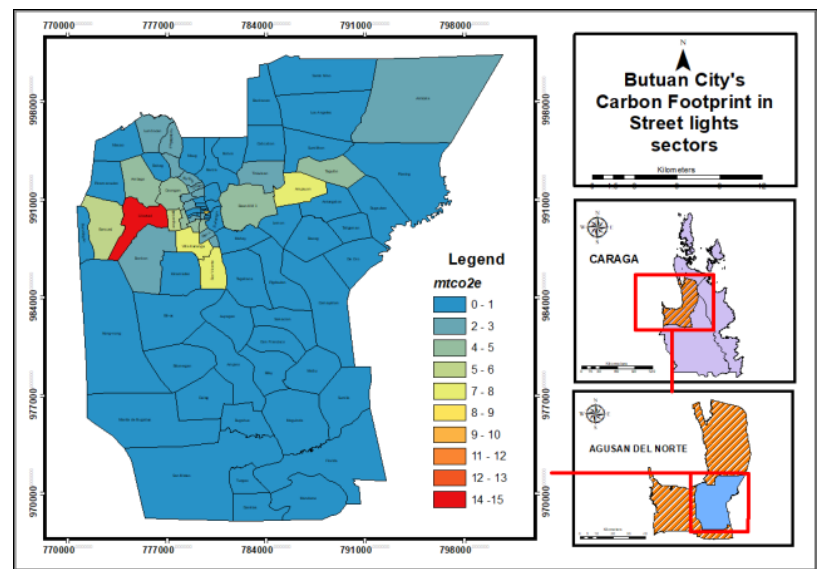

Figure 13. Spatial distribution of carbon footprint from street lights electricity consumption during COVID-19 lockdown (a month of April \& May-2020) in Butuan City.

\subsection{Correlation between lockdown and pre-lockdown period}

Figure 14a shows the total carbon footprint in the pre-lockdown period from January to April 2020. A carbon footprint's highest value is estimated in five Butuan barangays in descending order from the highest to lowest values. Barangay Bayanihan, Libertad, Imadejas, and Villa Kananga, and the lowest carbon footprint are Barangay Bitan-agan, Nongnong, Maibu, Don Francisco, and
Mandamo. In the lockdown period a month of March and April 2020, Libertad has the highest carbon footprint value, followed by Bayanihan, Baan Km3, and Villa Kananga. The lowest carbon footprint is Barangay Bitan-agan, Nongnong, Maibu, Don Francisco, and Mandamo, as shown in Figure 14b. The figure shows the carbon footprint impact saved during the lockdown period a month of March and April 2020. The impact savings of carbon footprint mainly occur in central and northern areas of Butuan City, specifically Barangay Bayanihan, Dagohoy, Agao, Silongan, Amparo, Taligaman, Sikatuna, Imadejas, Banza, and Diego Silang.

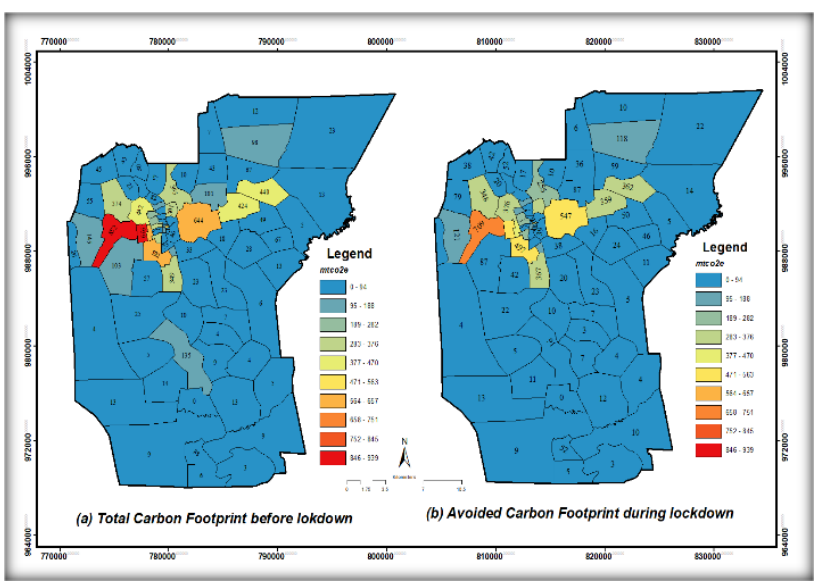

Figure 14. Spatial distribution of carbon (CF) impacts across 86 barangays areas in Butuan City: (a) Total carbon footprint calculated during pre- lockdown period (b) The carbon footprint impact saved during the lockdown period a month of March and April 2020.

The correlation coefficient $\mathrm{R}$ is the square roots of 0.9572 is 0.97837 , which shows that the relationship between prelockdown and lockdown period because the more substantial the correlation, the closer the correlation comes to +1 . Figure 15 shows that when the value of electricity consumption also decreases, the carbon footprint decrease, and if the electricity consumption increase also the carbon footprint increases.

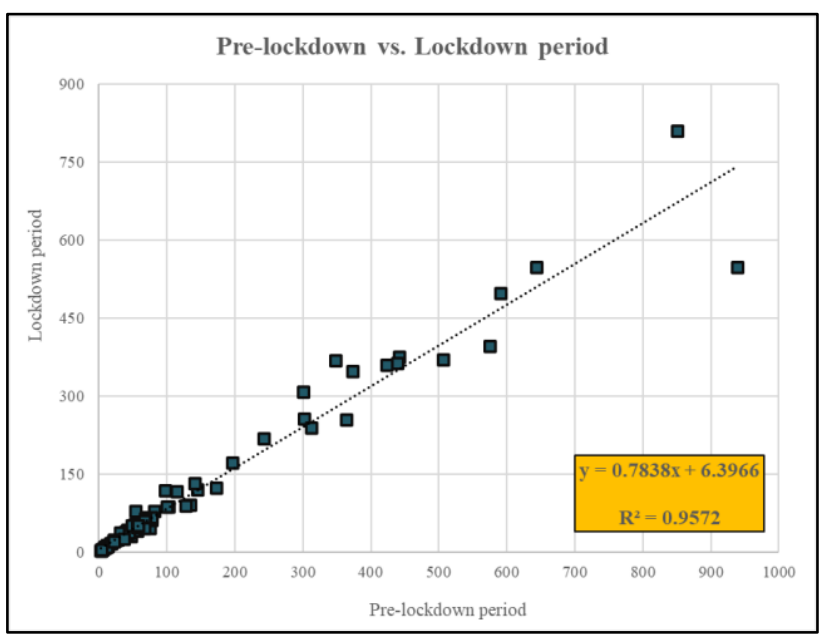

Figure 15. Correlation Between lockdown and prelockdown period 
Table 1 shows the calculated carbon footprint from pre-lockdown to lockdown period. There are percentage increases or decreases per barangay.

\begin{tabular}{|c|c|c|c|}
\hline BARANGAY & $\begin{array}{c}\text { PRE-LOCK } \\
\text { DOWN } \\
\text { PERIOD } \\
\text { (mtCo2e) } \\
\end{array}$ & $\begin{array}{c}\text { LOCK } \\
\text { DOWN } \\
\text { PERIOD } \\
(\mathrm{mtCo2e}) \\
\end{array}$ & $\begin{array}{c}\% \text { OF } \\
\text { INCREASE } \\
\text { OR } \\
\text { DECREASE } \\
\end{array}$ \\
\hline Agao & 48 & 31 & $-35 \%$ \\
\hline Agusan Pequeno & 72 & 61 & $-16 \%$ \\
\hline Ambago & 374 & 348 & $-7 \%$ \\
\hline Amparo & 135 & 91 & $-33 \%$ \\
\hline Ampayon & 425 & 356 & $-15 \%$ \\
\hline Anticala & 23 & 22 & $-5 \%$ \\
\hline Antongalon & 49 & 50 & $3 \%$ \\
\hline Aupagan & 10 & 10 & $3 \%$ \\
\hline Baan km3 & 644 & 547 & $-15 \%$ \\
\hline Baan Riverside & 52 & 52 & $0 \%$ \\
\hline Babag & 21 & 20 & $-5 \%$ \\
\hline Bading & 82 & 79 & $-4 \%$ \\
\hline Bancasi & 145 & 121 & $-17 \%$ \\
\hline Banza & 365 & 255 & $-30 \%$ \\
\hline Baobaoan & 7 & 6 & $-10 \%$ \\
\hline Basag & 28 & 24 & $-13 \%$ \\
\hline Bayanihan & 939 & 548 & $-42 \%$ \\
\hline Bilay & 9 & 7 & $-15 \%$ \\
\hline Bitan-agan & 5 & 22 & $-10 \%$ \\
\hline Bit-os & 25 & 5 & $-12 \%$ \\
\hline Bobon & 10 & 10 & $1 \%$ \\
\hline Bonbon & 103 & 87 & $-15 \%$ \\
\hline Bugsukan & 5 & 5 & $-2 \%$ \\
\hline Buhangin & 40 & 39 & $-1 \%$ \\
\hline Cabcabon & 43 & 36 & $-17 \%$ \\
\hline Camahayan & 6 & 5 & $-7 \%$ \\
\hline Dagohoy & 75 & 46 & $-39 \%$ \\
\hline Dankias & 6 & 5 & $-15 \%$ \\
\hline De oro & 13 & 11 & $-13 \%$ \\
\hline Diego Silang & 173 & 123 & $-29 \%$ \\
\hline Don Francisco & 4 & 3 & $-21 \%$ \\
\hline Doongan & 442 & 376 & $-15 \%$ \\
\hline Dulag & 14 & 11 & $-18 \%$ \\
\hline Dumalagan & 26 & 24 & $-7 \%$ \\
\hline Florida & 9 & 10 & $2 \%$ \\
\hline Golden Ribbon & 72 & 68 & $-6 \%$ \\
\hline Holy Redeemer & 197 & 173 & $-12 \%$ \\
\hline Humabon & 36 & 29 & $-21 \%$ \\
\hline Imadejas & 576 & 397 & $-31 \%$ \\
\hline JP Rizal & 303 & 256 & $-15 \%$ \\
\hline Kinamlutan & 57 & 42 & $-27 \%$ \\
\hline Lapu-lapu & 78 & 62 & $-20 \%$ \\
\hline Lemon & 18 & 16 & $-13 \%$ \\
\hline Leon kilat & 39 & 32 & $-17 \%$ \\
\hline Libertad & 852 & 809 & $-5 \%$ \\
\hline Limaha & 243 & 218 & $-10 \%$ \\
\hline Los Angeles & 98 & 118 & $21 \%$ \\
\hline Lumbocan & 43 & 42 & $-1 \%$ \\
\hline Maguinda & 13 & 12 & $-5 \%$ \\
\hline
\end{tabular}

\begin{tabular}{|l|c|c|c|}
\hline Mahay & 33 & 38 & $17 \%$ \\
\hline Mahogany & 301 & 308 & $2 \%$ \\
\hline Maibu & 4 & 4 & $0 \%$ \\
\hline Mandamo & 3 & 3 & $-1 \%$ \\
\hline $\begin{array}{l}\text { Manila de } \\
\text { Bugabus }\end{array}$ & 13 & 13 & $4 \%$ \\
\hline Maon & 53 & 52 & $-1 \%$ \\
\hline Maso & 45 & 38 & $-16 \%$ \\
\hline Maug & 17 & 17 & $-1 \%$ \\
\hline MJ Santos & 5 & 5 & $-7 \%$ \\
\hline $\begin{array}{l}\text { New society } \\
\text { Village }\end{array}$ & 61 & 53 & $-13 \%$ \\
\hline Nongnong & 4 & 4 & $0 \%$ \\
\hline Obrero & 142 & 132 & $-6 \%$ \\
\hline Ong Yiu & 78 & 67 & $-13 \%$ \\
\hline Pagatpatan & 50 & 52 & $5 \%$ \\
\hline Pangabugan & 115 & 116 & $2 \%$ \\
\hline Pianing & 13 & 14 & $4 \%$ \\
\hline Pigdaulan & 23 & 23 & $0 \%$ \\
\hline Pinamanculan & 55 & 79 & $44 \%$ \\
\hline Port Poyohon & 69 & 64 & $-6 \%$ \\
\hline Rajah Solimon & 57 & 48 & $-16 \%$ \\
\hline Salvacion & 7 & 7 & $0 \%$ \\
\hline San Ignacio & 63 & 48 & $-24 \%$ \\
\hline San Mateo & 9 & 9 & $-8 \%$ \\
\hline San Vicente & 349 & 367 & $5 \%$ \\
\hline Sikatuna & 129 & 89 & $-31 \%$ \\
\hline Silongan & 37 & 25 & $-34 \%$ \\
\hline Sto. Nino & 12 & 10 & $-15 \%$ \\
\hline Sumile & 5 & 4 & $-11 \%$ \\
\hline Sumlihon & 67 & 59 & $-12 \%$ \\
\hline Tagabaca & 23 & 20 & $-9 \%$ \\
\hline Taguibo & 440 & 362 & $-18 \%$ \\
\hline Taligaman & 67 & 46 & $-32 \%$ \\
\hline Tandang Sora & 314 & 238 & $-24 \%$ \\
\hline Tiniwisan & 101 & 87 & $-13 \%$ \\
\hline Tungao & 587 & 52 & $-11 \%$ \\
\hline Urduja & 370 & $-27 \%$ \\
\hline Villakananga & 497 & $-16 \%$ \\
\hline & & \\
\hline
\end{tabular}

Table 1. Summary of carbon footprint increase or decrease during pre-lockdown and lockdown periods.

Figure 16 shows the estimation of carbon footprint change by each barangay during pre-lockdown as compared during the lockdown period. Almost all the barangay during the lockdown period with decreasing carbon footprint.

The estimation of carbon footprint changes by each barangay during pre-lockdown compared to during the lockdown period. Almost all of the barangay during the lockdown period was decreasing their carbon footprint. The highest reduction of the impact of carbon footprint during the lockdown period was Barangay Bayanihan which has $42 \%$ shown in Figure 17. Furthermore, the highest impact of carbon footprint increase was Barangay Pinamanculan which has $44 \%$ mtco2e shown in Figure 18. 


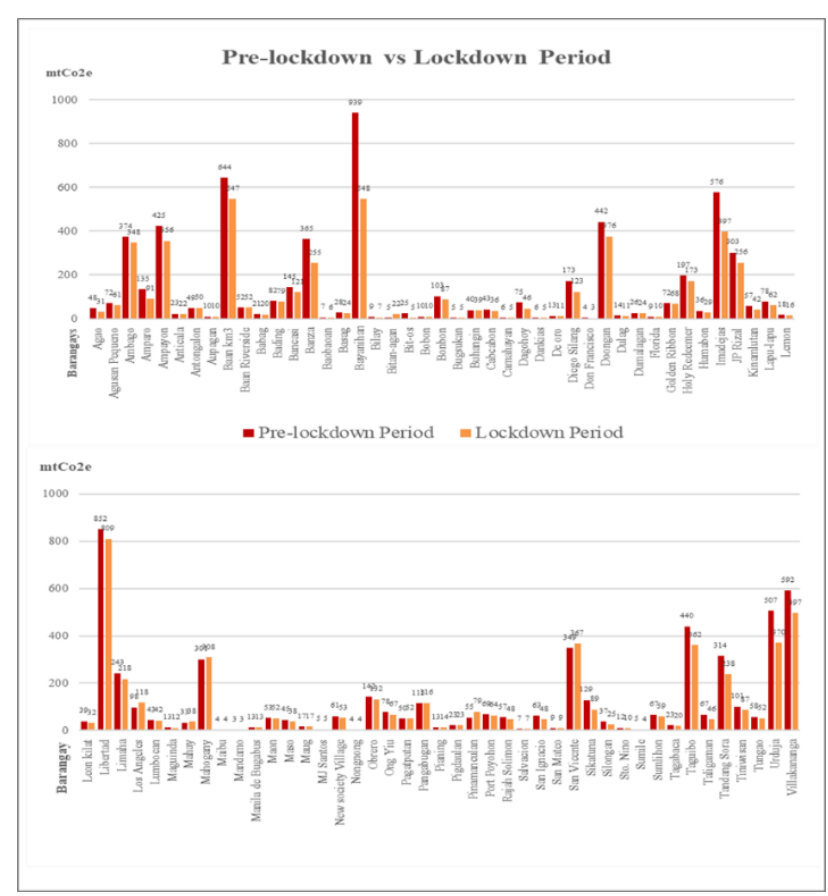

Figure 16. Carbon Footprint across 86 barangays in Butuan City during pre-lockdown vs. lockdown periods.

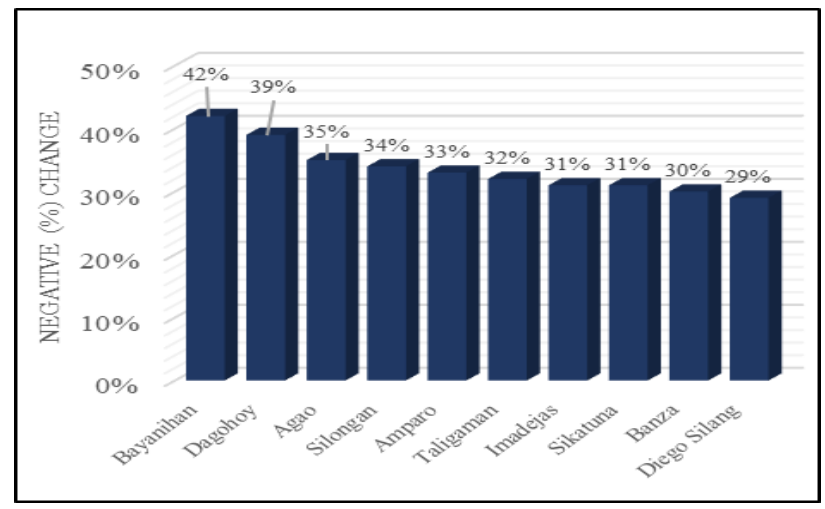

Figure 17. Top 10 barangays with decreasing carbon footprint in the lockdown period.

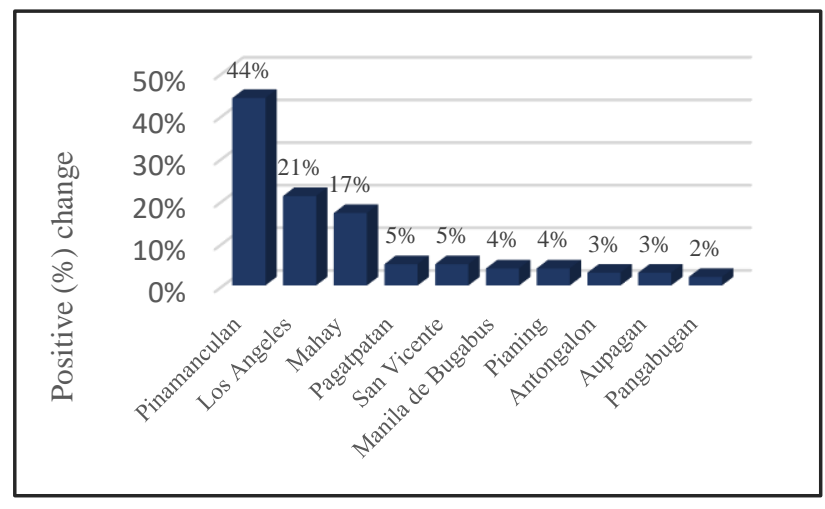

Figure 18. Top 10 barangays with increasing carbon footprint

\section{CONCLUSION}

This study has estimated a relevant decrease in the carbon footprint of around $17 \%$ compared with the pre-lockdown and lockdown period, a month of January to April 2020. It has been mainly due to a significant reduction in electricity consumption. Central and northern in Butuan City has been the area with the highest emissions avoided during the lockdown period. The calculated carbon footprint during the pre-lockdown and lockdown period was $\sim 10,947 \mathrm{mtco} 2 \mathrm{e}$ and $\sim 9,138 \mathrm{mtco} 2 \mathrm{e}$, respectively. Residential has the highest share in carbon dioxide emission during the lockdown period, with $50 \%$ of the total carbon footprint during the lockdown period.

Generally, this study has focused on estimating carbon footprint during the pre-lockdown period (January and February 2020) and lockdown period (March and April 2020). The analysis considered the comparison of carbon footprint in lockdown and pre-lockdown periods. Identify the area with the highest carbon footprint impact and determine the prevented carbon dioxide emission in the lockdown period.

\section{REFERENCES}

Biradar, S.K., "Brackish water aquaculture site selection in Palghar Taluk, Thane District of Maharashtra, India, using the techniques of remote sensing and geographical information system," Aquaculture. Engg, pp. 285-305, 2005.

Carugno, M., Randi, D., Catelan, L., and Grissoto, "Air pollution exposure, cause-specific deaths and hospitalization in highly polluted italian region," Environmental Res., vol. IV, no. 147, pp. 415-424, 2020.

Contini, D., and Costabile, F., "Does air pollution influenced COVIDF-19 outbreaks?" Atmosphere 11, no. 11, pp. 377-388, 2020.

E. S. R. Institution, "ArcGIS; acomplete integrated system," http://www.esri.com/software/arcgis/, 2009.

Marc, R. "Spatial Distribution of Energy Consumption and Carbon Emission of Regional Logistics," Sustainability 2015, vol. 7, pp. 3-4, 2015.

Mulrow, J., Machaj, K., Deanes, J., and Derrible, S., "The state od Carbon calculator: An Evaluation of Calculator design and user Interaction," pp. 13-14, 2017.

Mylenka, T., "Impact of COVID-19 on the global energy sector," energy. Res, 2020.

Richard, V., Filimonau, D., Archer, L., Bellamy, N., and Smith, "The carbon footprint of a UK University during the COVID-19 lockdown," Science of Environment, vol. 756, no. February 2021, 143964, 2020.

Z. Zhu, L. Wang, and X. Yang, "A novel coronavirus from a patient with pneumonia in china," vol. III, no. 382, pp. 727-733, 2019. 